\title{
Collaboration Among Community Members, Local Health Service Providers, and Researchers in an Urban Research Center in Harlem, New York
}

SANDRO GALEA, MD, MPH

Stephanie H Factor, MD, $\mathrm{MPH}^{\mathrm{a}, \mathrm{c}}$

Sebastian Bonner, PhD

Mary Foley, EDD d,e

Nick Freudenberg DrPH ${ }^{\mathrm{e}, \mathrm{f}}$

Mary Latka, PhD ${ }^{a}$

Ann-Gel Palermo, MPH ${ }^{\mathrm{e}, \mathrm{g}}$

David Vlahov, PhD

\section{SYNOPSIS}

The Urban Research Center at the Center for Urban Epidemiologic Studies brings together community members and researchers working in Harlem, New York. A Community Advisory Board (CAB) composed of community members, service providers, public health professionals, and researchers was formed to assist the Center's research and interventions and to guide community partnerships. Through a collaborative process, the CAB identified three public health problems-substance use, infectious diseases, and asthma-as action priorities. To deal with substance use, the Center created a Web-based resource guide for service providers and a "survival guide" for substance users, designed to improve access to community services. To deal with infectious diseases, the Center is collaborating with local community-based organizations on an intervention that trains injection drug users to serve as peer mentors to motivate behavior change among other injection drug users. To deal with asthma, the Center is collaborating with community child care providers on an educational intervention to increase asthma awareness among day care teaching staff, enhance communication between staff and families, and improve the selfmanagement skills of children with asthma. The Center's experience has demonstrated that active communities and responsive researchers can establish partnerships that improve community health.

${ }^{a}$ Center for Urban Epidemiologic Studies, New York Academy of Medicine, New York, NY

${ }^{b}$ Department of Epidemiology, Columbia University Mailman School of Public Health, New York, NY

'Division of Preventive and Analytic Methods, Epidemiology Program Office, Centers for Disease Control and Prevention, Atlanta, GA

${ }^{\mathrm{d} D e p a r t m e n t ~ o f ~ C o m m u n i t y ~ a n d ~ P r e v e n t i v e ~ M e d i c i n e, ~ M o u n t ~ S i n a i ~ S c h o o l ~ o f ~ M e d i c i n e, ~ N e w ~ Y o r k, ~ N Y ~}$

${ }^{\mathrm{e} C o m m u n i t y ~ A d v i s o r y ~ B o a r d, ~ C e n t e r ~ f o r ~ U r b a n ~ E p i d e m i o l o g i c ~ S t u d i e s, ~ N e w ~ Y o r k ~ A c a d e m y ~ o f ~ M e d i c i n e, ~ N e w ~ Y o r k, ~ N Y ~}$

fProgram in Urban Public Health at Hunter College, City University of New York, New York, NY

${ }^{g}$ Institute for Medicare Practice, Mount Sinai School of Medicine, New York, NY

Address correspondence to: Sandro Galea, MD, MPH, Center for Urban Epidemiologic Studies, New York Academy of Medicine, 1216 Fifth Ave., Rm. 556, New York, NY 10029-5293; tel. 212-822-7378; fax 212-876-6220; e-mail <sgalea@nyam.org>.

The authors thank all members of the Community Advisory Board who contributed to the projects described here. The authors are also indebted to Mary Northridge, PhD, MPH, for her comments on an earlier version of this manuscript. This work was funded in part by Centers for Disease Control and Prevention Urban Research Centers Cooperative Agreement U48/CCU209663-07. 
East and Central Harlem in New York City have among the highest rates of infant mortality, HIV/AIDS, asthma hospitalizations, and homicides in the city of New York and the United States. ${ }^{1,2}$ Both communities have longestablished community service agencies and a history of social activism that aims at improving socioeconomic conditions and health. ${ }^{3}$

To help understand and improve public health in Harlem, researchers and community members joined together to form an Urban Research Center. The experience of the researchers and community service providers involved in the Center can help others develop a deeper understanding of the process by which research linkages between academia and practice contribute to better research and improved health outcomes. ${ }^{4-6}$

\section{DEVELOPING THE INSTITUTIONS NEEDED TO IMPLEMENT CHANGE}

\section{Center for Urban Epidemiologic Studies}

The Center for Urban Epidemiologic Studies (CUES), located in East Harlem, was established by the New York Academy of Medicine in 1996 to promote research collaborations among medical institutions in New York City and to conduct research on the health of city residents. The Center's initial thrust was to conduct research on a wide range of health problems, including breast cancer, hypertension, and racial disparities in health.

The initial proposal did not emphasize community involvement in research and did not specify a relationship between CUES and the Harlem community. Researchers at CUES were instrumental in shaping the early evolution of the Center and increasing communication with community members. By the end of 1998, CUES had changed its leadership and modified its direction. As early projects developed, CUES formed relationships with Harlem networks, including the East Harlem Community Health Committee and the East and Central Harlem HIV Care Networks, as well as with long-established community-based organizations, including Settlement Health and Medical Services, Inc., and the Boriken Neighborhood Health Center.

CUES formalized these relationships by creating a Community Advisory Board (CAB) composed of individuals from community organizations, consumers, public health professionals, and researchers. By 1999 the $\mathrm{CAB}$ was providing input for all CUES projects. Community partners also participated in the design and implementation of certain projects. These changes in work process reflected a change in CUES's mission. The changes were encouraged by the Centers for Dis- ease Control and Prevention (CDC), both through its role as a funder and through its assignees at CUES, who worked collaboratively with researchers and community organizations.

In 1999, CDC issued a request for proposals emphasizing collaborative relationships with community groups and participatory research models. This Urban Research Center Cooperative Agreement, for which CUES successfully competed, built on the Center's evolving strengths and further encouraged community-academic collaboration. This collaboration, structured along formal community-based participatory research principles, ${ }^{7}$ has evolved to reflect both the strengths of the various partners involved and the lessons learned in the process of implementing new projects.

\section{Urban Research Center}

Coincident with the evolution of CUES into a research center that worked collaboratively with the local community, CUES researchers and CAB members started to identify appropriate action priorities for a Harlem Urban Research Center. The CAB reviewed needs assessments of the community conducted during the preceding decade. It also sought input from and engaged in discussions with established community leaders and service providers.

Several health issues of community concern were identified through these needs assessments and discussions. From them the CAB chose substance use, infectious diseases, and asthma as priorities for research.

\section{Evolution of the $\mathrm{CAB}$ and a model of the social determinants of health}

Meetings of the CAB throughout 1999 and 2000 focused on three activities. First, the $\mathrm{CAB}$ actively sought to define its role and establish a mission and operating principles. Development of the operating principles required evaluation and discussion of the collaborative relationship among community members, local health service providers, and institutional researchers. An early version of $\mathrm{CAB}$ operating principles formulated by a $\mathrm{CAB}$ subcommittee was refined through an iterative consensus-building process during monthly meetings. The issues raised often shed light on the evolving relationship between the $\mathrm{CAB}$ and the Harlem community. For example, although it was clear at the outset that community members and researchers would collaborate on projects, the role each would play in the partnership was subject to discussion. It was eventually decided that "the $\mathrm{CAB}$ shall serve as a resource to the [Urban Research Center] 
research staff on the unique living conditions ... of Harlem." This was complemented by the decision that the Center "shall serve as a resource to community organizations, and residents" (Figure 1). Thus, community members on the $\mathrm{CAB}$, working together with institutional researchers, envisioned that their collaborative efforts could serve as a resource for the community as part of the process toward improving health in Harlem.

Initial operating principles were adopted in 1999 and revised and updated in 2001. The $\mathrm{CAB}$ mission statement was adopted in 2001 (Figure 2). Formulating these principles and mission served two purposes. First, in the process of discussing competing visions of collaboration, all $\mathrm{CAB}$ members had the opportunity to critically evaluate how they could contribute to a more effective collaboration. Second, the finished documents have since served as a touchstone for all $\mathrm{CAB}$ members, with the principles frequently referred to in discussion to ground debate and inform decisions about undertaking new projects.

The second activity CAB undertook during 19992000 was development of a model of social determinants of health to provide a theoretical research framework. Using discussions, focus groups, and literature from preventive medicine, public health, and sociology, the $\mathrm{CAB}$ developed a model that incorporated social factors relevant to health. At early $\mathrm{CAB}$ meetings, social factors important to health in Harlem were discussed and potential research interventions iden-

\section{Figure 1. Operating principles of the Urban Research Center Community Advisory Board}

I. The purpose of the Urban Research Center (URC) Community Advisory Board (CAB) is to ensure that the Harlem community has an active voice in the URC and its operations and that the URC has an ongoing presence in the community via the CAB.The community within which we will conduct public health research is currently defined as, but not limited to, all of Harlem.

II. The purpose of any research conducted is to benefit the community, either through increased knowledge or by promoting better health.

III. The purpose of participatory research is to develop a partnership of community-based organizations, public health agencies, and educational and other relevant institutions that can work together to study and improve community health.

IV. The CAB should consist of local community-based organizations, public health agencies, educational institutions, and local residents.

V. The CAB shall serve as a resource to the URC research staff on the unique daily living conditions, needs, strengths, and community dynamics of the Harlem community and other related geographical areas.

VI. The URC shall serve as a resource to community organizations and residents, conducting training on the principles of research, including grant-writing, the institutional review board process, informed consent, and how to collect, analyze, interpret, report, and disseminate data to enhance individual and/or organizational capacity to conduct research that benefits the community.

VII. On all of its products, the URC will consult with, invite to collaborate as co-author (where appropriate), and acknowledge the contribution of all partners that participate in the research.

VIII. The URC has an obligation to disseminate findings in a timely manner through community forums, community newsletters, and other community events.

IX. All URC research projects will meet current ethical standards and will fully respect the rights of all participants in a culturally sensitive manner, including the rights to be aware of risks and benefits, to give informed consent, and to have the option to withdraw from research at any time without penalty to the participant.

X. The community partners will be educated about the institutional review board process and informed consent whenever research ideas are conceptualized.

$\mathrm{XI}$. The members of the CAB will be involved in all phases of URC research activities, including defining the problem; gathering data; analyzing data; using, interpreting, and disseminating results; program development and evaluation; and strategies to advocate for policies to improve health.

XII. The CAB will contribute to the evaluation of all URC activities, including the community-based participatory research model of the URC.

XIII. Participating research partners are not limited to members of the CAB, and, in fact, involvement of local residents, other community-based organizations, other public agencies, and other educational and other relevant institutions are encouraged as long as the above principles are followed. 
tified. These ideas were then revised and presented to the group at subsequent meetings.

The model of social determinants developed by the $\mathrm{CAB}$ incorporated such social factors as access to services, quality of living area, social support, and discrimination, which affect individual health (Figure 3). Fundamental causes (money, power, prestige) were incorporated to reflect factors affecting all other levels of the model, including communities and individuals. As have the operating principles and mission, the model of social determinants has provided a common ground for all members in the collaboration. The model helps to structure thinking and debate and suggests potential research and interventions.

The CAB's third activity was the development of specific research projects to study and intervene in selected components of the model of social determinants of health. In keeping with the priority areas of need identified earlier, principal $\mathrm{CAB}$ projects focused on substance use, HIV and hepatitis C, and asthma. Within each of these priority areas, research and intervention were structured to address the social factors that were hypothesized to affect health in Harlem.

\section{SUBSTANCE USE}

Priority setting, focus groups, and surveys

Substance use has long been a serious problem in East and Central Harlem, contributing to high rates of HIV, homicides, other forms of violence, and other public health problems. ${ }^{8}$ The Harlem Household Survey, conducted in Central Harlem in 1992-1994, revealed that $10 \%$ to $35 \%$ of respondents ages 18 to 65 had used heroin or cocaine during their lifetimes. These self-reported prevalences are 4 to 10 times as high as those reported by respondents in surveys of New York City overall and the United States during the same period. ${ }^{9}$ Rates of drug abuse-related hospitalizations in East and Central Harlem in 1996 (34 per 1,000 adults ages 25-44 in East Harlem; 28 per 1,000 adults in Central Harlem) were three times as high as rates in New York City as a whole and the highest in the city. ${ }^{10}$

Substance use has been hypothesized as being a direct precursor of poor health and a contextual factor contributing to the social environment, which, in turn, affects health. Specifically, social factors, such as poverty or neighborhood physical conditions, have been reported to affect rates and patterns of morbidity and the adoption of risk behaviors. ${ }^{11,12}$ Substance use is also thought to be a consequence of socioeconomic conditions. ${ }^{13-15}$ Substance use thus shapes and is shaped by the social environment. This bidirection- ality, emphasized in the general model of social determinants developed by the CAB (Figure 3), has guided intervention research at the Urban Research Center.

One of the key social factors identified by the $\mathrm{CAB}$ in the model of social determinants was access to services, which was perceived to be important to the health of substance users. We conducted two surveys to identify barriers substance users encounter in accessing services. Using information obtained in focus groups and in-depth one-on-one interviews with substance users, we developed one survey instrument for substance users and another for service providers. A detailed description of the methodology and results has been published elsewhere. ${ }^{16}$ Briefly, service providers and substance users agreed that there was a lack of available information about and barriers to accessing job training, job opportunities, housing services, and services for ex-convicts. The experience of $\mathrm{CAB}$ members also suggested the need to improve job opportunities, housing, and services for drug users with complex problems. The findings from the surveys and the reports from the $\mathrm{CAB}$ led to three early interventions: the Breaking the Barriers symposium, a survival guide for substance users, and a Web-based resource guide for service providers.

\section{Breaking the Barriers symposium}

Breaking the Barriers was a community symposium organized by the $\mathrm{CAB}$ that provided a forum for substance users, community service providers, and policy makers interested in the prevention and treatment of substance use in Harlem. CAB members invited residents of the community and representatives of other service agencies to serve as both facilitators and participants.

\section{Figure 2. Mission statement of the Urban Research Center's Community Advisory Board}

The Urban Research Center Community Advisory Board is committed to

- ensuring the active reciprocal relationship between the Harlem community and the Urban Research Center

- promoting public health research to benefit the community through increasing health awareness and by promoting better health outcomes

- using participatory research to develop a partnership with community-based organizations, public health agencies, and educational and other relevant institutions to study and improve community health. 
The symposium, held October 26-27, 2000, brought together about 150 consumers, service providers, and policy makers in addition to public health professionals and researchers. The New York State Commissioner of Health was the keynote speaker. Workshop participants focused on such issues as jobs, housing, and education in discussing barriers to services and potential solutions. The symposium was the first public activity that the $\mathrm{CAB}$ organized, and it introduced the $\mathrm{CAB}$ to the community. Discussions during the symposium often included exchanges among substance users, service providers, and state administrators that generated ideas for intervention and insights that continue to be debated today.

\section{Survival Guide for substance users}

The Survival Guide is an intervention for substance users that improves informational social support and access to services. Based on research from surveys and focus groups, this educational intervention provides information on promoting health and obtaining specific services. Modeled on the Wellness Guide introduced in California, ${ }^{17}$ the Survival Guide was developed by users for users. Substance users involved in early focus groups continue to be involved in shaping the design and content of the guide as it nears completion.

The guide is divided into three sections. The first section includes health education information on such topics as safe injection practices, HIV, hepatitis B and $\mathrm{C}$, and tuberculosis. The second section offers a reference list of community services, including drug treatment and needle-exchange programs, housing agencies, and job placement services. The third section includes relevant "hotline" numbers. A street look with graffiti and mature cartoons was suggested by users and will be adopted for the guide. Ongoing art workshops, facilitated by a community artist, involve users in guiding the graphic content of the guide. The artist was selected by the $\mathrm{CAB}$ and regularly reviews progress and evolving artwork with a $\mathrm{CAB}$ subcommittee. A randomized controlled trial will determine the effectiveness of the guide by measuring substance use and sexual behaviors and knowledge of and access to community services before and after introduction of the guide.

\section{Web-based resource guide for service providers}

Survey research and CAB members' experience indicated that service providers needed a tool for making referrals. Our survey of service providers found that although $90 \%$ of providers had computers in their offices, only $18 \%$ used the Internet to find information for client referrals. More than half of providers
(58\%) reported that an Internet database of available services in Harlem would be useful.

To address these needs, the CAB began to develop a Web-based guide specific to East and Central Harlem to help community service providers refer substance users to social services. For this project, the CAB principally collaborated with the East Harlem Community Health Committee to update their 1994 publication of substance treatment programs. This updated publication was then computerized and demonstrated to service providers and substance users at the Breaking the Barriers symposium to obtain user and provider feedback. A revised version of the database has recently been disseminated more widely to community members and service agencies to solicit additional feedback. A finished database will be publicized and made available to all service providers in the community in both Web format and hard copy. A follow-up survey of community service providers will evaluate the usefulness of the two versions six months after the resource guide is available.

\section{Policy research and future substance use interventions}

Our model acknowledged the role of public policies in facilitating or blocking access to substance use services and in the quality of those services. To assess the importance of various policies in this area, researchers and $\mathrm{CAB}$ members designed a survey to elicit the perceptions of service providers. Seventy-five community service providers at substance use treatment facilities and health and social service agencies-including both front-line staff and managers-were interviewed. Respondents identified three main sets of policies as limiting their ability to connect drug-using clients to needed services: policies of drug treatment agencies (e.g., not offering child care for women in treatment); correctional policies (e.g., lack of discharge planning for drug-using inmates released from jail); and health insurance policies (e.g., long waiting periods to establish eligibility for Medicaid). These findings will be used to develop and evaluate an intervention designed to change policies that limit access to substance use services.

\section{HIV AND HEPATITIS C}

Harlem has been disproportionately affected by both HIV and hepatitis C, a major cause of chronic hepatitis and cirrhosis. ${ }^{18}$ In New York City, $47 \%$ of all reported cases of AIDS are caused by injection drug use.$^{19}$ Hepatitis $\mathrm{C}$ is currently primarily transmitted by injection drug use. ${ }^{20-23}$ Two HIV and hepatitis C studies are currently being conducted at CUES. 


\section{Harlem outreach and prevention education/hepatitis $\mathrm{C}$ study}

In the first ongoing study, young (18-29) non-injecting or recently initiated injecting drug users are being studied to determine risk factors for hepatitis $\mathrm{C}$ infection and initiation into injection drug use. Risk factors among noninjection drug users will be determined by examining sexual and drug use behaviors, social networks, history of physical and sexual abuse, and level of psychiatric comorbidity. All participants are offered appropriate counseling and referral to community services. The studies are conducted out of two research storefronts in the community. Storefront staff, primarily community members, work with other service agencies to recruit participants.

\section{Drug-Users' Intervention Trial (DU-IT)}

The second ongoing study is intended to reduce sexual and injection risks associated with HIV and hepatitis $\mathrm{C}$ among injection drug users. This study uses a two-arm randomized trial design to evaluate the effectiveness of a peer educator intervention. All trial participants receive standard-of-care enhanced pre- and post-test HIV and hepatitis C counseling, after which eligible participants are randomized to either a treatment or a control condition. Participants are recruited directly from the community. Storefront staff and CAB members encourage participation from service agencies represented on the $\mathrm{CAB}$ and in the community. Participants in both arms attend six two-hour small group sessions. Participants in the control arm view videos on violence and drug policy and participate in facilitated small group discussions. Participants in the experimental arm receive training to become peer educators and participate in a one-week field placement at a community organization, e.g., a needle exchange program.

This intervention research has been designed to motivate and sustain behavior change based on a harmreduction philosophy, using interactive exercises, including games, facilitated discussions, viewing and critiquing of specially designed videos, and behavioral modeling with corrective feedback as well as skillbuilding for safer injection and sex practices. The intervention involves a one-time placement of a peer educator at a local community-based organization that provides services to injection drug users. Collaboration between researchers organizing the study and community organizations participating in the study is thus strengthened. Researchers hypothesize that participants will achieve sustained reduction in their risk behaviors as a result of their increased familiarity and comfort with these agencies.
This project addresses a different component of the model of social determinants from the one addressed by the substance use projects. Specifically, DUIT addresses personal factors, including both risk behavior and adoption of preventive behavior, as areas for intervention. The intervention is based on the premise that building individual competency and offering the opportunity to try on a new, positive social role will improve personal factors that will improve outcomes (Figure 3) ${ }^{24,25}$ It also draws on research that has found that those who help are helped the most. ${ }^{26,27}$ Thus, although it is hoped that the participants' immediate peers and community benefit from peer education, the primary goal of the study is to reduce risk behavior among the peer educators themselves. Participants also develop relationships with their host community organizations-relationships that reinforce safer behavior through continued social support, access to clean injection equipment and condoms, screening for and treatment of sexually transmitted disease, and referrals to drug and medical treatment.

Although the trial is designed to assess changes in the incidence of hepatitis $\mathrm{C}$, changes in behavioral outcomes, which are often more proximal to risk, will also be measured. Injection-related behavioral risk factors to be investigated are the proportions of injections done with used syringes and the number of people with whom the user shares needles. Sexual behavioral outcomes to be assessed include the number and proportion of unprotected sex acts by gender and partner type. Participants in both arms of the trial complete a baseline interview and return at three, six, and 12 months to assess post-intervention change.

\section{ASTHMA}

\section{Pediatric asthma in Harlem}

Pediatric asthma, a leading cause of hospitalizations, emergency department visits, and school absence among children, has a substantial impact on East and Central Harlem. ${ }^{28}$ In addition to pharmacologic therapy and trigger avoidance, key components of asthma care include health education and partnerships between patients and providers..$^{28}$ Early recognition and control of asthma might have long-term benefits in reducing the risk for irreversible airway remodeling. ${ }^{29}$

This project involves a collaboration between CUES researchers and two early child care providers in East and Central Harlem. The intervention involves the development of a tool to screen children for asthma and an educational intervention to improve parentprovider partnerships. 
Figure 3. Model of social determinants developed by the Urban Research Center Community Advisory Board

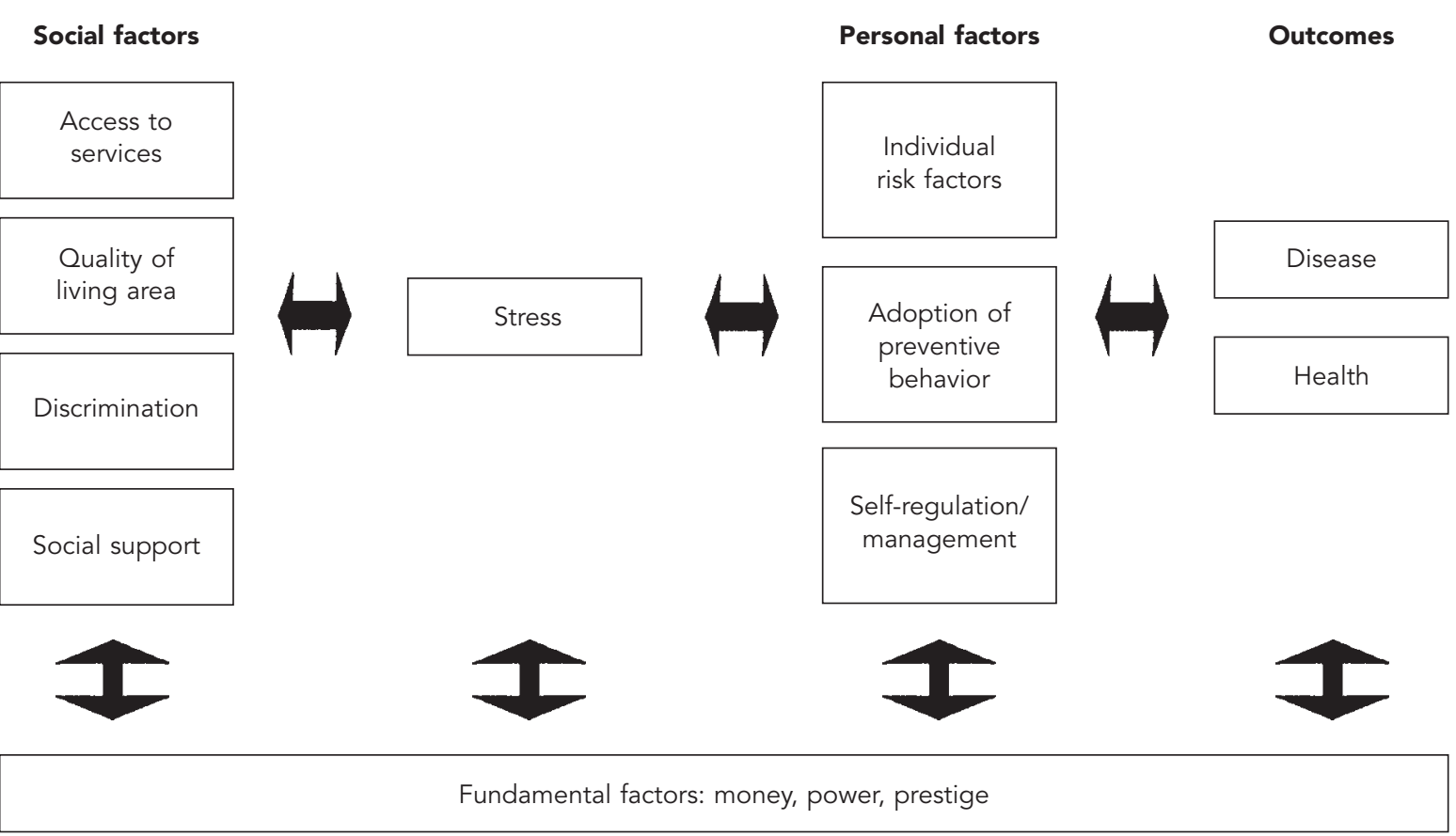

Reprinted from Galea S, Factor SH, Palermo A-G, Aaron D, Canales E, Vlahov D. Access to resources for substance users in Harlem, NYC: service provider and client perspectives. Health Educ Behav 2002;29:296-311.

\section{Collaboration}

In response to community advocacy, Urban Research Center behavioral scientists, epidemiologists, and physicians experienced in asthma education collaborated with managerial staff members from child care providers in Harlem to devise a program for preschool-age children with asthma. Collectively, they planned a screening and education intervention, implementation of which relied primarily on the staff of two early child care centers. CUES led the effort in applying for funding and gaining approval from institutional review boards. The project was funded by the CDC, with subcontracts to the two early child care providers. Conceptually, this project aimed to improve selfregulation, one of the personal factors identified in the model of social determinants.

Through the project's preparation and implementation phases, mechanisms were developed to promote collaboration between researchers and community providers. A project management team including research investigators and the providers' managerial staff meets biweekly to identify and resolve obstacles to program implementation. An intervention team composed of researchers, health educators, and family services workers from the provider organizations meets weekly to discuss case management and program progress, ensuring that the intervention remains responsive to providers' needs and the research design. For example, the number of staff training workshops was increased and the format of the parent education workshops altered in response to calls from provider representatives on the team. At the request of the researchers on the team, the lines of authority within the provider organizations were redrawn to allow family services workers to report asthma-related concerns directly to their center directors.

Preliminary data documenting levels of participation have led to adaptations that have reduced the burden of the intervention on the staff and to a focus on children identified with persistent symptoms that might indicate uncontrolled asthma. During the data analysis phase, mechanisms to promote collaboration between researchers and providers will be used to assess the utility of the screening tool and the effectiveness of the educational intervention and to provide information on how the educational intervention may be sustained after the research has been completed. This project is being evaluated in several ways: by validating the screening tool against clinical evaluation by three physicians of parental reports of children's symp- 
toms and medication use; by measuring screening tool utilization once the validation research is completed; and by conducting follow-up at four, eight, and 12 months based on institutional records of attendance and parental reports of symptoms and medication use.

This collaboration benefits community child care providers in several ways. First, it improves the likelihood that health education initiatives will be based on careful research findings and respond to parents' needs. Second, by drawing on provider staff skills, this collaboration may offer new insights on how to weave health initiatives into the existing structure of community organizations rather than imposing them from above. Finally, and perhaps most important, this collaboration develops ties between CUES and leading community organizations in Harlem whose programs are affected by an urban epidemic.

\section{DISCUSSION}

As a result of changes in focus and increasing interaction with community organizations in East and Central Harlem, CUES is now a different organization from the one founded in 1996. We have encountered obstacles and have learned several lessons during this transformation. The perspectives of both researchers and $\mathrm{CAB}$ members have helped us draw these lessons, some of which may be applicable to other communityacademic partnerships. ${ }^{6}$

Lesson 1: Developing a dialogue and engaging a dedicated core group are the first steps in building a meaningful relationship between researchers and community members. The early stages of developing the $\mathrm{CAB}$ were not always straightforward. Community-based organizations were initially reluctant to have staff members attend regular $\mathrm{CAB}$ meetings, subcommittee meetings, and other related activities during working hours; child care and family responsibilities made evening meetings infeasible. Early $\mathrm{CAB}$ meetings suffered from high turnover, as members quit because of lack of rapid progress. Eventually, the ongoing dialogue among members served to establish the $\mathrm{CAB}$ as a viable body with regular membership. Driving this dialogue was a growing appreciation of the advantages of collaborative work and the role collaborative work played in addressing social factors that affect health. In this regard, establishing operating principles and a shared model of social determinants represented time well spent. The process of formally articulating shared principles and beliefs about factors that affect health served to clarify roles and responsibilities and to engage a core group of $\mathrm{CAB}$ members who remain active in $\mathrm{CAB}$ activities.
Lesson 2: Focusing initially on priority health areas identified by community members and service providers is essential to build credibility and address issues that matter to the community. Researchers and community representatives sometimes disagreed over areas of focus for the collaboration. CUES's early focus, for example, was on health problems such as hypertension and breast cancer. These interests have since given way to priorities that represent an intersection of those perceived by community members and researchers. Although ongoing respectful discussion provided a forum for finding common ground, some early contributors to the collaboration (including community members, service providers, and researchers) left the $\mathrm{CAB}$ because their interests were not aligned with the direction the group had chosen. The projects the $\mathrm{CAB}$ is currently involved in represent a collective vision that these issues are important and can be effectively addressed through our work.

A second consideration is the approach taken to address or research health areas of interest. Our experience suggests that both community members and researchers have unique and complementary insights into the causes of and solutions to public health problems. In addition, funder priorities inevitably guide the activities undertaken, all of which need to bid for competitive funding. Having an agreed upon model of social determinants has frequently served to ground discussion and focus proposed projects.

Lesson 3: Negotiating consensus takes time. Stakeholders bring opinions from disparate perspectives that are, at times, difficult to reconcile. Finding an appropriate balance between discussion and action requires energy and goodwill on the part of all involved, but agreeing on common ground is essential for the collaborative relationship. People who have participated in a consensus-building process ultimately have a stake in the success of the project and are more likely to become involved in project design and execution.

A corollary to this lesson is that early, tangible success is at times essential to sustaining enthusiasm among all members of the collaboration. Although the operating principles and the model of social determinants have been tremendously helpful, work on these conceptual issues could not have proceeded in isolation. It was decided early on in the CAB that work on process and structure could be done while research interventions were developed. The $\mathrm{CAB}$ has been actively discussing its own internal functioning for the past two years; the model of social determinants is being revisited and by-laws that stem from the operating principles are being finalized. A traditional operating 
style would suggest that the $\mathrm{CAB}$ needed to fully develop its mission statement and operating principles before becoming involved in any research or intervention. Such a delay would have been unsatisfying for all involved, however. An open dialogue allowed research and $\mathrm{CAB}$ development to proceed simultaneously.

A second corollary to this point is that engaging community members and researchers in the process of building a shared conceptual model of disease is possible and perhaps critical to a long-term successful collaboration. This process took time and demanded willingness on the part of both researchers and community partners to approach these problems from each others' perspective. Researchers encountered crossdisciplinary differences in designing an etiologic model of social determinants; community members faced daily realities that frequently elevated to prominence certain factors (such as poverty) above all others. Solutions were found thorough discussion, drawing on the published literature in various disciplines, personal experiences, and an analysis of existing needs assessments and data in Harlem.

Lesson 4: Direct and meaningful access to the community on multiple levels is needed to perform substantive research interventions, particularly on social factors and health. Social factors are embedded in the local social environment, including the immediate physical environment, cultural milieu, and interpersonal relationships. ${ }^{30}$ Researchers need partnerships with community members to help them understand relevant features of the social environment. Similarly, although participation in community coalitions can help organizations such as CUES become acquainted with the local community, ongoing relationships with community-based organizations and key individuals in the community are necessary for research and intervention. The asthma intervention involves active partnerships with community organizations that are not formally linked to the CAB. Similarly, the infectious disease research projects, which function out of project storefronts in Harlem, continually rely on other community organizations to recruit and refer participants. These collaborations have not always been easy. The establishment of a research storefront in Central Harlem was initially perceived as a threat to long-established service agencies. Researchers' willingness to listen to community organizations was key to the storefronts' evolution. Individual social service providers also recognized the potential benefits of this work for the community and have now become active members of the $\mathrm{CAB}$. They continue to serve as liaisons between the researchers and their agencies.
Lesson 5: Collaborative work between researchers and community members requires ongoing education of both parties. Researchers need to learn about community culture. Community members need to become familiar with research protocols, institutional review board procedures, and the conventions of empirical research. Community partners and researchers can serve as resources for one another. Community members in the $\mathrm{CAB}$ can guide researchers in understanding how factors investigated in other communities may apply to the local community. CUES researchers provide support for $\mathrm{CAB}$ staff and community-based organizations by writing grant proposals and designing and conducting studies. These activities build sustainable capacity for research that goes beyond the immediate involvement of CUES.

Community members and researchers sometimes have different criteria for success-one of the key barriers encountered early in the collaborative relationship. Researchers value gaining new understanding of a problem, while community residents put a high priority on bringing direct benefits to the community. For example, community members devoted significant energy to the development of a survival guide for substance users, but it was often harder to achieve active community involvement in infectious disease research. Researchers and community members eventually came to embrace both projects and to understand how their aims were complementary. This understanding of the two groups' complementary roles was facilitated by education of both parties: researchers learned that the transience of service agencies made a Web-based resource guide an essential piece of the fabric of service provision in Harlem, while community members came to understand the gaps in knowledge about infectious disease transmission that the research sought to fill. Successful partnerships need to find a balance between these two outcomes that represents both academic and community priorities.

\section{CONCLUSION}

CUES has evolved from a traditional medical research institution into one that engages in community collaboration for the direction, design, and implementation of its projects. The Center has identified and designed projects that are responsive to the surrounding community and has involved community members in all elements of research. The process of establishing a participatory model in a community in which many residents and activists distrusted established medical institutions inevitably encountered successes and failures. While it is too soon to assess whether our 
efforts will lead to measurable improvements in community health, it is clear that researchers, service providers, and community residents have begun a deeper and more sustained dialogue on the causes of and solutions to this community's health problems.

\section{REFERENCES}

1. United Hospital Fund. Community health atlas. New York: United Hospital Fund; 1999.

2. Centers for Disease Control and Prevention (US). Division of HIV/AIDS Prevention. Basic statistics [cited 2002 Jun 14]. Available from: URL: http://www.cdc.gov/hiv /stats.htm

3. Higgins DL, Metzler M. Implementing community-based participatory research centers in diverse urban settings. J Urban Health 2001;78:488-94.

4. Yin RK. Case study research: design and methods. Thousand Oaks (CA): Sage; 1994.

5. Fulbright-Anderson K, Kubish AC, Connell JP, editors. New approaches to evaluating community initiatives. Queenstown (MD): Aspen Institute; 1998.

6. Freudenberg, N. Case history of the Center for Urban Epidemiologic Studies in New York City. Urban Health 2001;78:508-18.

7. Israel B, Schulz A, Parker EA, Becker AB. Review of community-based research: assessing partnership approaches to improve public health. Annu Rev Public Health 1998;19:173-202.

8. Fullilove MT, Green L, Fullilove RE. Building momentum: an ethnographic study of inner-city redevelopment. Am J Pub Health 1999;89:840-4.

9. Fullilove RE, Fullilove MT, Northridge ME, Ganz ML, Bassett MT, McLean DE, et al. Risk factors for excess mortality in Harlem: findings from the Harlem Household Survey. Am J Prev Med 1999;16(3 Suppl):22-8.

10. Community Health Profile: Manhattan. New York (NY): NYC Turning Point Project; 1999.

11. Davey Smith G, Hart C, Watt G, Hole D, Hawthorne V. Individual social class, area-based deprivation, cardiovascular disease risk factors, and mortality: the Renfrew and Paisley study. J Epidemiol Commun Health 1998; 52:399-405.

12. Cohen D, Spear S, Scribner R, Kissinger P, Mason K, Wildgen J. "Broken windows" and the risk of gonorrhea. Am J Public Health 2000;90:230-6.

13. Bachman JG, O'Malley PM, Johnston LD. Drug use among young adults: the impacts of role status and social environment. J Pers Soc Psych 1984;47:629-45.

14. Bourgois P. In search of respect: selling crack in El Barrio. New York (NY): Cambridge University Press; 1995.

15. Wallace R, Fullilove MT, Wallace D. Family systems and deurbanization: implications for substance abuse. In: Lowinson JH, Ruiz P, Millman RB, editors. Substance abuse: a comprehensive textbook. 2nd ed. Baltimore: Williams and Wilkins; 1992. p. 944-57.

16. Galea S, Factor SH, Palermo A-G, Aaron D, Canales E, Vlahov D. Access to resources for substance users in Harlem, NYC: service provider and client perspectives. Health Educ Behav 2002;29:296-311.

17. Neuhauser L, Schwab M, Syme SL, Beiver M. Community participation in health promotion: evaluation of the California Wellness Guide. Health Promotion Int 1998;13:211-21.

18. New York City Department of Health, Office of AIDS Surveillance. Estimates of persons living with AIDS in NYC: 1998. New York: New York City Department of Health; 1999.

19. New York City Department of Health, Office of AIDS Surveillance. AIDS NYC. AIDS surveillance update: first quarter 1998. New York: New York City Department of Health; 1998.

20. Van der Poel CL, Cuypers HTM, Reesink HW, Choo QL, Kuo G. Han J, et al. Risk factors in HCV infected blood donors. Transfusion 1991;31:777-9.

21. Esteban JL, Loper-Talavera JC, Genesca J, Mudoz P, Viladomiu L, Muniz E, et al. High rate of infectivity and liver disease in blood donors with antibodies to hepatitis C virus. Ann Intern Med 1991;151:443-9.

22. Villano SA, Vlahov D, Nelson KE, Lyles CM, Cohn S, Thomas DL. Incidence and risk factors for hepatitis $\mathrm{C}$ among injection drug users in Baltimore, Maryland. J Clin Microbiol 1997;35:3274-7.

23. Alter MJ. Epidemiology of hepatitis C. Hepatology 1997;26:62S-5S.

24. Auerback JD, Wypijewska C, Brodie H, Hammond K, editors. AIDS and behavior: an integrated approach. Washington: National Academy Press; 1994.

25. Myers DG. Social psychology. New York (NY): McGrawHill; 1987.

26. Sikkema KJ, Kelly JA, Winett RA, Solomon LJ, Cargill VA, Roffman RA, et al. Outcomes of a randomized community-level HIV prevention intervention for women living in 18 low-income housing developments. Am J Public Health 2000;90:57-63.

27. Kelly J, Lawrence J, Diaz Y, Stevenson Y, Hauth A, Brasfield TL, et al. HIV risk behavior reduction following intervention with key opinion leaders of population: an experimental analysis. Am J Public Health 1991;81:168-71.

28. Stevenson L, Kaminsky M. Asthma hospitalization and mortality in NYC, 1987-1996. Presented at Working Together to Combat Urban Asthma conference; 1998 May 4; New York, NY.

29. Roberts CR, Okazawa M, Wiggs B, Paré PD. Airway wall thickening. In: Barnes PJ, Grunstein NM, Leff AR, Woolcock AJ, editors. Asthma. Vol. 1. Philadelphia: Lippincott-Raven; 1997. p. 925-35.

30. Barnett E, Casper M. A definition of "social environment.” Am J Public Health 2001;91:465. 